\title{
Lack of word-superiority effect in processing letter features
}

\author{
F. PERESSOTTI and R. JOB \\ University of Padua, Padua, Italy
}

Letter recognition is typically faster in words than in nonwords. In this study, we tested the word-superiority effect obtained when either subletter features or misalignment of letters had to be detected. Subjects were presented with both high- and low-frequency words and with legal and illegal nonwords. Space among the letters varied. In the regular space condition, letters within a string were separated by normal spaces; in the irregular space condition, letters were separated by normal spaces, small spaces, or large spaces. In Experiment 1, subjects were required to detect the presence of a bold segment contained in one of the letters of the string. No wordsuperiority effect was obtained. Furthermore, spacing affected neither latencies nor response accuracy. In Experiment 2, subjects were required to detect the presence of a letter misaligned with respect to the others. Again, no word-superiority effect was obtained. However, spacing affected this task, irregularly spaced strings being responded to more slowly and less accurately than regularly spaced strings. The results indicate that at the first stages of analysis, words and nonwords are similarly coded. The pattern obtained is consistent with a multistage model of word recognition in which parallel feature extraction processes are followed by a level at which spatial relationships are computed and by a third level at which abstract grapheme identity is recovered from letter shapes.

Since Cattel's studies of 1886 , the problem of determining which visual characteristics of a word are encoded during reading has become a central issue of cognitive psychology. The word-superiority effect (WSE)-the higher detectability of letters when they are contained in words-is a well-studied phenomenon (for a review, see Carr, 1986). Advantages of words over single letters (Johnston \& McClelland, 1973; Prinzmetal, 1992) and over orthographically regular (Estes \& Brunn, 1987; Solman, 1987) and irregular nonwords (Baron \& Thurston, 1973; Marchetti \& Mewhort, 1986; Sphoer \& Smith, 1975) have been reported. The WSE over nonwords in letter detection is manifested both in latencies of letter search tasks (Krueger, 1992) and in accuracy in forcedchoice procedures (Reicher, 1969). The effect could be due either to an enhanced visual perceptibility of words (i.e., the physical characteristics of words actually provide a more perceptible stimulus) or to verbal and/or lexical factors, and hence dependent on more abstract computations.

The processes involved in the analysis of visual information are often regarded as roughly hierarchical. Feature extraction processes such as edge and blob detection, texture, size, and color information are commonly thought to be computed during the initial stage of visual analysis. On the other hand, the high-level processes such as object (or word) recognition are thought of as the end product and they can no longer be considered purely visual,

Correspondence should be addressed to F. Peressotti, Dipartimento di Psicologia dello Sviluppo e della Socializzazione, Via Beato Pellegrino, 26, 35137 Padua, Italy. since they require access to long-term memory representations. However, other computational problems need to be solved between these two levels. The features extracted must be processed and conjoined, and the spatial relationships among them must be computed in order to obtain shape description and object segmentation (Marr, 1982; Treisman, 1986). Following this approach (see Caramazza \& Hillis, 1990; Monk, 1985), word recognition could be thought of as a process that begins with the extraction of simple visual features such as letter segments, lines, and edges; at a second level, these features are conjoined so that the spatial relationships among them are computed in order to construct letter shapes; at a final level, the graphemes are recovered from letter shapes and an ordinate sequence of graphemes is built, so that the mental lexicon can be accessed. According to such a multistage model, the computations at the various levels are affected by different factors. In particular, while visual and spatial factors should affect processing at the first and second stages of analysis, respectively, linguistic variables should become relevant only at later stages, when visual shapes are recognized as letters and their identity is computed. So, according to this view, at the early visual coding stages words and nonwords are processed analogously, and, therefore, a WSE can originate only after letter shapes have been computed-that is, when graphemes are recovered.

Recently, Mewhort and Johns (1988) have proposed that word activation is not based on the activation of letter units alone, but that it depends, at least in part, on information at the feature level. So, according to these authors, the WSE originates at the feature extraction stage, even if, 
as the authors admit, it is not clear how information at this level may contribute to the effect.

In the following experiments, we tried to test these alternative predictions. Subjects were presented with sevenand five-letter strings, which could consist of either highand low-frequency words or orthographically regular and irregular nonwords. All the strings were displayed twice, once with normal spaces among the letters, and once with extra spaces among the letters. In the latter condition, spaces were added quasirandomly so that two letters could be separated by one space, two spaces, or no space. Two different tasks were devised. In the first experiment, subjects had to detect the presence of a bold segment contained in one of the letters of the string. In the second experiment, they had to detect the presence of a letter located two pixels above the baseline. These two tasks were assumed to tap different stages of processing. A bold segment could be detected during the processes of feature extraction, whereas to detect an elevated letter, the spatial relationships among features and letter shapes would have to be computed.

If the WSE depends on visual low-level processes, we could expect that both a bold segment and an elevated letter could be detected more easily in words than in nonwords. On the other hand, if the WSE depends on more abstract computations, as suggested by the multistage model previously outlined, lexical and/or linguistic variables should affect neither the bold segment detection task nor the elevated letter detection task, since visual and spatial analyses precede the linguistic analysis of the stimulus.

Furthermore, according to the multistage model, spacing among letters should have a different effect in the two tasks. It should influence the elevated letter detection task, since such a task requires the computation of spatial relationships among letter shapes. However, it should not influence the bold segment detection task for which no interletter spatial relationships need to be computed.

\section{GENERAL METHOD}

\section{Apparatus and Display Conditions}

The experiment was controlled by a Macintosh Classic computer. The stimuli were displayed on the screen, which was placed approximately $65 \mathrm{~cm}$ from the eyes of the subject. The fixation point was a plus sign appearing in the center of the screen for $500 \mathrm{msec}$. Five hundred milliseconds after its offset, the stimulus followed at the same location. The stimulus consisted of a string of either five or seven letters. When displayed, a letter on the screen subtended a visual angle of $0.54^{\circ}$ vertically and $0.45^{\circ}$ horizontally. The space between letters varied between conditions. In one condition, the interletter space was constant and subtended always $0.17^{\circ}$ (normal spacing condition). In the other condition, the interletter space subtended $0.17^{\circ}$ (no interletter space), $0.35^{\circ}$ (small interletter space), or $0.70^{\circ}$ (large interletter space). Interletter spaces varied randomly within each string, with the constraint that for the fiveletter strings, the letters and spaces added up to 9 characters, and that for the seven-letter strings, the letters and spaces added up to 12 characters. Therefore, the five-letter strings subtended approximately $2.93^{\circ}$ and $4.29^{\circ}$ in the normal and extraspace conditions, respectively. The seven-letter strings subtended approximately $4.17^{\circ}$ and $6.27^{\circ}$ in the normal and extra space conditions, respectively. All strings were displayed in uppercase (font, MicroBoston 24), presented for $200 \mathrm{msec}$ in a darkon-light format, and followed by a 200 -msec pattern mask that covered the same spatial region as did the stimuli. The mask was generated by randomly orienting letter segments.

The low rightmost key (KeyPad) and the low leftmost key (Control) of the keyboard were selected as response buttons. The keyboard was placed in front of the subject.

\section{Stimuli}

A total of 288 letter strings were used, 168 seven-letter strings and 120 five-letter strings. The strings were either words or nonwords and were classified into four classes: high-frequency words, low-frequency words, legal nonwords, and illegal nonwords. The seven-letter string list contained 42 items in each class. The five-letter string list contained 30 items in each class. For word frequencies, Bortolini, Tagliavini, and Zampolli's (1972) corpus was used (for high-frequency words, mean frequency $=106.01$; for low-frequency words, mean frequency $=$ 1.80). Legal nonwords were created by changing one or two letters of real words. Illegal nonwords consisted of consonant sequences.

Half the stimuli were experimental items, and half, fillers. In the experimental items, one of the letters of the string was the target letter. It could occupy any position in the string, with the constraint that there were 12 items per position equally distributed between the types of string (i.e., 3 items for each type of string). Target letter identity and position were constant between the four types of strings. The target letters were always $\mathbf{M}, \mathrm{T}, \mathrm{R}$, or $\mathrm{A}$. Given these stimuli, it was possible to test the same letters at all serial positions in each of the four context conditions. Accordingly, any difference in the context conditions cannot be due to testing different letters or different positions.

The 288 letter strings were always presented twice-once with normal spaces among letters, once with extra spaces among letters.

\section{Experimental Design}

The experimental design was a repeated measures design with three within-subjects factors: spacing (normal spacing, extra spacing), number of letters (five-letter strings, seven-letter strings), and type of string (highfrequency words, low-frequency words, legal nonwords, illegal nonwords). The significance level for statistical analyses was set at $p<.05$.

\section{Procedure}

Each subject was presented with four blocks of strings: five-letter strings with normal spaces among letters; five-letter strings with extra spaces among letters; seven-letter strings with normal spaces among letters; seven-letter strings with extra spaces among letters. The order of block presentation was balanced within subjects. Items within a block were randomized before each presentation. Subjects were allowed $1,000 \mathrm{msec}$ for responding. If the subject did not respond within that time, a deadline sound announced the next trial. Response times and accuracy were both recorded.

At the beginning of the session, two training lists containing 40 items each were presented. The items in the first list had normal spaces among the letters, and the items in the second list had extra spaces among the letters. After each practice and experimental block of stimuli, the subject had a rest period of approximately $4 \mathrm{~min}$. The overall session took $45 \mathrm{~min}$.

\section{Subjects}

A total of 32 subjects, undergraduate students at the University of Padua, participated in the study in order to fulfill a course requirement. Separate groups of 16 subjects were used in each experiment and were tested in a single experimental session. Their ages ranged between 20 and $\mathbf{3 0}$ years. All participants had Italian as their first language, and had either normal or corrected-to-normal vision.

\section{EXPERIMENT 1}

\section{Method}

In the experimental items, the target letter contained a bold segment (see examples in Table 1).

The subjects were requested to press the left key ("Yes" response) when detecting the bold segment and the right key if the string did not appear to contain any bold segment ("No" response). 
Table 1

Exemplars of Experimental Items Containing Target Letters from Experiment 1 (left) and Experiment 2 (right)

\section{NEONATO}

CAVALLO

\section{NEONATO}

CRACCIA
CRACCIA
CAVALLO

\section{Results}

Figure 1 shows correct mean response times for the detection of the bold segment and error rates averaged over subjects. Two analyses of variance (ANOVAs) were performed, one on RTs and one on error percentages arcsine transformed, with spacing (normal or extra spacing), number of letters (five- or seven-letter strings), and type of string (high-frequency words, low-frequency words, legal nonwords, or illegal nonwords) as within-subjects factors.

No main effect or interaction reached significance, either in the ANOVA of RTs (all $F \mathrm{~s}<1$ ) or in the ANOVA of errors [all $F \mathrm{~s}<1$, except for spacing, $F(1,15)=1.78$, type of string $F(3,45)=1.41$, and spacing $\times$ number of letters, $F(1,15)=1.89$ ].

\section{EXPERIMENT 2}

\section{Method}

In the experimental items, the target letter was elevated two pixels above the baseline (see Table 1). Letters in the filler items were placed on the same baseline, but one of them was two pixels higher than the others, thus protruding from the superior edge of the string as did the elevated letter. Therefore, detection of the elevated letter should have been based on analyzing the spatial relationships among letter shapes and could not have been based on judging the spatial extent of the vertical area occupied by the stimulus in a retinally projected image. The subjects were requested to press the left key ("yes" response) if one of the letters of the string was elevated and the right key otherwise ("no" response).

\section{Results}

Figure 2 shows mean latencies for the detection of the elevated letter and error percentages in the different experimental conditions. On these data, two ANOVAs were performed, as in Experiment 1.

The ANOVAs of RTs showed significant main effects of spacing $\left[F(1,15)=8.813, M S_{\mathrm{e}}=6,908.747\right]$ and number of letters $\left[F(1,15)=8.153, M S_{\mathrm{e}}=1,251.183\right]$. Faster response times were obtained in the normal spacing condition than in the extra spacing condition ( $425 \mathrm{vs.}$ $456 \mathrm{msec}$ ), and faster response times were obtained with five-letter strings than with seven-letter strings ( $435 \mathrm{vs.}$ $447 \mathrm{msec}$ ). These results were confirmed by the ANOVA of error percentages arcsine transformed. Again there were significant effects of spacing $[F(1,15)=35.027$, $\left.M S_{\mathrm{e}}=0.209\right]$ and of number of letters $[F(1,15)=$ 25.707, $\left.M S_{\mathrm{e}}=0.111\right]$. In the normal spacing condition and in the extra spacing condition, the mean error percentages were $9 \%$ and $19 \%$, respectively. The five-letter

string and seven-letter string conditions had $11 \%$ and $16 \%$ error, respectively.

In order to conclude that spacing among letters is a variable that affected the computations in Experiment 2 but not in Experiment 1, an ANOVA comparing the two experiments was performed with experiment as a betweensubjects factor and spacing, number of letters, and type of string as within-subjects factors. The only significant sources of variance were the main factor, experiment $\left[F(1,30)=21.73, M S_{\mathrm{e}}=41,894.42\right]$, and the interaction of experiment $\times$ spacing $\left[F(1,30)=7.166, M S_{\mathrm{e}}=\right.$

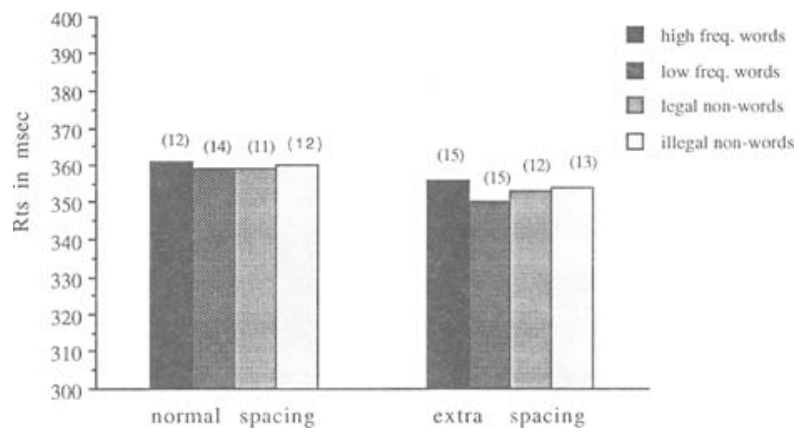

Figure 1. Response times and error percentages (in parentheses) obtained in the experimental conditions of Experiment 1.

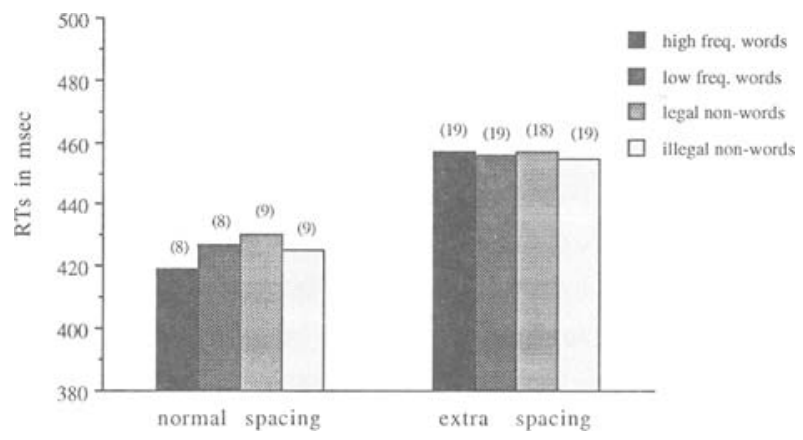

Figure 2. Response times and error percentages (in parentheses) obtained in the experimental conditions of Experiment 2.

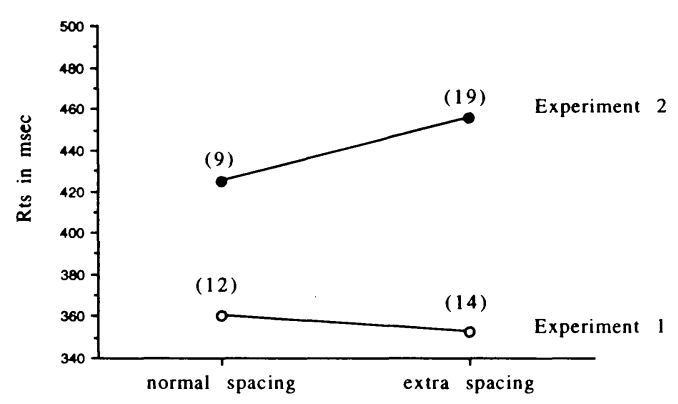

Figure 3. Response times and error percentages (in parentheses) obtained in the normal and extra spacing conditions of Experiments 1 and 2. 
44,831.408]. Faster response times were obtained in Experiment 1 than in Experiment 2 (357 vs. $441 \mathrm{msec}$, respectively). More interestingly, as shown in Figure 3, whereas the difference between normal and extra spacing conditions was not significant in Experiment 1, it was so in Experiment 2.

\section{DISCUSSION}

No WSE is found when subjects are required to detect a subletter unit or a misalignment of a letter within a string. In addition, while the former task is not affected by the spatial arrangement of letters within the string, detecting an elevated letter is more difficult in an irregularly than in a regularly spaced string.

Asking subjects to judge features of letters, rather than letters, makes the WSE disappear. This suggests that at the earlier stages of processing, words' and nonwords' sublexical features are computed analogously. This conclusion qualifies in one important respect the claim put forward by Mewhort and Johns (1988) and reported above. According to these authors, the WSE depends, at least in part, on information at the feature level. They based this conclusion on the fact that the WSE was reduced when words were presented in mixed case. However, our results suggest that the type of feature and/or the requirement of the task play a crucial role in determining whether sublexical features intervene in the WSE. Mewhort and Johns used a forced-choice task that required subjects to recognize letters. The tasks in the present experiments required subjects to analyze subletter units. This difference seems to be crucial for the WSE to be obtained.

In relation to the processing of spatial information in letter strings, the question of why spacing affected subjects' responses only in Experiment 2 needs to be answered. Our explanation refers to the distinction between a first stage of processing, tapped by the bold segment detection task, and a later stage, tapped by the elevated letter detection task. In the first, the relevant visual features are extracted in parallel from the discontinuities of light intensities and represented in a retinally projected image; therefore, spatial information either between or within letter shapes is not computed. Spatial information instead is processed at the second stage, in which the spatial position of each element with respect to the other elements, independently of the absolute position on the retina, is computed.

\section{REFERENCES}

BARON, J., \& ThURSTON, I. (1973). An analysis of the word-superiority effect. Cognitive Psychology, 4, 207-228.

Bortolini, U., Tagliavini, C., \& Zapolli, A. (1972). Lessico di frequenza della lingua italiana contemporanea. Milan: Garzanti.

Caramazza, A., \& Hilus, A. E. (1990). Levels of representation, coordinate frames, and unilateral neglect. Cognitive Neuropsychology, 7, $391-445$.

CARR, T. H. (1986). Perceiving visual language. In K. R. Boff, L. Kaufman, \& J. P. Thomas (Eds.), Handbook of perception and human performance (chap. 29, pp. 1-92). New York: Wiley.

ESTES, W. K., \& BRUNN, J. L. (1987). Discriminability and bias in the word-superiority effect. Perception \& Psychophysiscs, 42, 411-422.

Johnston, J. C., \& MCCLELland, J. L. (1973). Visual factors in word perception. Perception \& Psychophysiscs, 14, 365-370.

KRUEGer, L. E. (1992). The word-superiority effect and phonological recoding. Memory \& Cognition, 20, 685-694.

Marchetti, F. M., \& Mewhort, D. J. K. (1986). On the wordsuperiority effect. Psychological Research, 48, 23-35.

MARR, D. (1982). Vision. New York: W. H. Freeman.

MewhorT, D. J. K., \& Johns, E. E. (1988). Some tests of the interactive activation model for word identification. Psychological Research, 50, 135-147.

MoNk, A. F. (1985). Theoretical note: Coordinate systems in visual word recognition. Quarterly Journal of Experimental Psychology, 37A, 613-625.

Prinzmetal, W. (1992). The word-superiority effect does not require a T-scope. Perception \& Psychophysics, 51, 473-484.

REICHER, G. M. (1969). Perceptual recognition as a function of meaningfulness of stimulus material. Journal of Experimental Psychology, 81, 275-280.

Solman, R. T. (1987). Temporal separation of two-part letter arrays and size changes in a nonmasking word-superiority effect. Perception, 16, 655-669.

SPHOER, K. T., \& SMITH, E. E. (1975). The role of orthographic and phonotactic rules in perceiving letter patterns. Journal of Experimental Psychology: Human Perception \& Performance, 104, 21-34.

Treisman, A. (1986). Features and objects in visual processing. Scientific American, 255, 106-115.

(Manuscript received April 30, 1993.) 